\title{
Effect of Ultrasonic Peening on Residual Stresses at a T-Butt Weld Toe
}

\author{
Alan K. HELLIER ${ }^{1, a *}$, B. Gangadhara PRUSTY1,b ${ }^{1, b a r t h ~ M . ~ P E A R C E ~}{ }^{1, c}$, \\ Mark REID ${ }^{2, \mathrm{~d}}$, Anna M. PARADOWSKA ${ }^{1,2, \mathrm{e}}$ and Peter SIMONS ${ }^{3, \mathrm{f}}$ \\ ${ }^{1}$ School of Mechanical and Manufacturing Engineering, UNSW Australia, (The University of New \\ South Wales), Sydney, NSW 2052, Australia \\ ${ }^{2}$ Bragg Institute, Australian Nuclear Science and Technology Organisation (ANSTO), Lucas \\ Heights, NSW 2234, Australia \\ ${ }^{3}$ Applied Ultrasonics Australia, Suite 11/20 Narabang Way, Belrose, NSW 2085, Australia \\ aa.hellier@unsw.edu.au, b.prusty@unsw.edu.au, co.pearce@unsw.edu.au, \\ dmarkr@ansto.gov.au, eanp@ansto.gov.au, fpsimons@appliedultrasonics.com.au
}

Keywords: A350 Grade, Black Mild Steel Plate, T-Butt Welded Joint, Ultrasonic Peening, Residual Stresses, Fatigue Crack Growth, Parametric Equations

\begin{abstract}
The current paper presents the results of neutron diffraction measurements of the throughthickness residual stress field at the toe of a T-butt weld, made from $10 \mathrm{~mm}$ thick A350 grade black mild steel plates, after successful ultrasonic peening. A single ultrasonic peening treatment was carried out at the weld toe. Residual stresses were measured using the KOWARI instrument at ANSTO. The neutron diffraction technique was chosen for this study because of its ability to measure three-dimensional residual stress deep within the component at high resolutions.

Although the nominal yield stress of the A350 grade plate is $350 \mathrm{MPa}$ the actual yield stress is generally higher, in this case averaging out to about $400 \mathrm{MPa}$. Ultrasonic peening was highly effective, leading to a residual stress redistribution with a maximum compressive stress of about $250 \mathrm{MPa}$ at the weld toe surface and a maximum tensile stress of $220 \mathrm{MPa}$, at a depth of almost $3 \mathrm{~mm}$ into the base plate. The resulting compressive residual stresses at the weld toe surface will almost certainly increase substantially both the fatigue initiation and propagation lives, or may prevent fatigue completely. Since A350 steel is widely used in buildings, bridges and offshore structures, ultrasonic peening shows great promise as an in-situ peening method in order to improve weld fatigue performance.
\end{abstract}

\section{Introduction}

A350 grade black mild steel is one of the most widely used structural materials in the world, being commonly found in buildings, bridges and offshore structures. Welding is typically used to join two plates of structural steel and this often takes the form of a T-butt weld. In addition, other more complex geometrical joints are often simplified for stress analysis purposes by approximating them as two-dimensional T-butt plate models (e.g. skewed T-joints, tubular welded joints, pipe-plate joints, etc.). However, all such welds are potentially susceptible to fatigue crack initiation and slow but accelerating growth arising as a result of fluctuating service loads, often eventually resulting in fast fracture.

Ultrasonic peening, more properly known as ultrasonic impact treatment (UIT), is a recent development of the well-established shot peening process. It was originally invented in 1972 in the former USSR to improve the fatigue and corrosion performance of ship and submarine hulls. UIT is similar to conventional needle or hammer peening in many respects. An important difference is that rather than using a pneumatic tool, which causes the needles or a single hammer-like rod to impact 
the weld surface at a frequency of $25-100 \mathrm{~Hz}$, with UIT, the weld is impacted by a small number of rods vibrating at a much higher frequency on the order of 18,000-27,000 Hz. This makes it a much quieter device, which vibrates at a lower intensity, so that the operator can use it for longer periods of time before tiring [1]. Ultrasonic peening is relatively cheap, can be applied in-situ and offers significant improvements in the lifespan of welded components when applied correctly. This occurs for three different reasons: removal of weld defects; reduction of stress concentration; and redistribution of tensile stresses and/or introduction of compressive stresses [2].

\section{Experimental Methods}

Welding. Dimensions were $800 \times 160 \times 10 \mathrm{~mm}$ for the base plate and $100 \times 160 \times 10 \mathrm{~mm}$ for the attachment plate of each T-butt. During fabrication two base plates were tack welded back-to-back prior to welding of the double-beveled attachment plate to each, in order to minimize distortion. Balanced full-penetration GMAW fillet welding was employed, with six passes on each side. All welds passed ultrasonic testing (UT) for internal flaws and magnetic particle inspection (MPI) for surface flaws. Fig. 1 shows the weld detail of a typical T-butt joint before buffing.

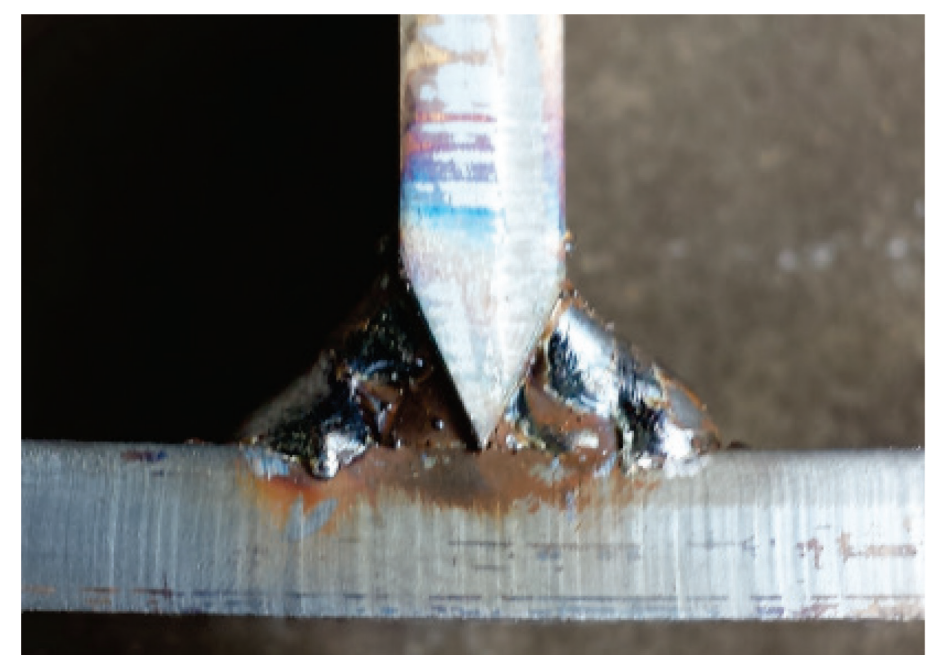

Fig. 1. Weld detail of typical T-butt joint before buffing.

Ultrasonic Peening. Ultrasonic peening treatments were carried out at the base plate and attachment plate weld toes on both sides of one of the T-butts using an Applied Ultrasonics Esonix UIT apparatus. The impact pins were oriented $45^{\circ}$ from the treated weld area (perpendicular to the toe line) and the tool was continuously moved in an oscillating motion in a path parallel to the direction of the weld. In order to develop the desired groove, the tool was worked back and forth between a $30^{\circ}$ and a $60^{\circ}$ angle while maintain the oscillating motion described above. Groove formation was continuously observed during the application process. A properly formed, shiny groove at the weld toe was obtained; this is the main quality assurance inspection point for treatment verification [3].

Neutron Diffraction. It was attempted to measure through-thickness residual stresses from the weld toe into the base plate for both as-welded and ultrasonically peened specimens using the KOWARI instrument at the ANSTO Bragg Institute. The (non-destructive) neutron diffraction technique was chosen for this study because of its ability to measure three-dimensional residual stress deep within the component at high resolutions. For the neutron measurements a $0.5 \times 0.5 \times 1 \mathrm{~mm}^{3}$ gauge volume was used for the longitudinal, transverse and normal components. The experimental measurements on the ultrasonically peened sample were successful but those on the as-welded sample were unfortunately shown to be incorrect, as the scan was made slightly inside the weld rather than exactly at the weld toe. 
Parametric Equations. Brennan-Dover-Karé-Hellier (BDKH) parametric equations [4] are available for the stress intensity factor (SIF) geometric Y-factor at the deepest point of a semi-elliptical flaw at the toe of a T-butt weld, accurate for a wide range of geometric parameters under both tension (membrane) and pure bending loadings. These were derived from the results of eighty 8-noded shell finite element analyses in conjunction with the Niu-Glinka weight function [5]. From the models studied, the geometry validity limits for the equations developed are:
Weld angle:
$30^{\circ} \leq \alpha \leq 60^{\circ}$
Crack aspect ratio:
$0 \leq a / c \leq 1.0$
Crack depth:
$0.01 \leq a / T \leq 1.0$
Weld toe radius:
$0.01 \leq \rho / T \leq 0.066$
Attachment width:
$0.3 \leq L / T \leq 4.0$

Fig. 2 shows the geometry of the T-butt weldments studied including the crack geometry, with all the geometric parameters above defined.
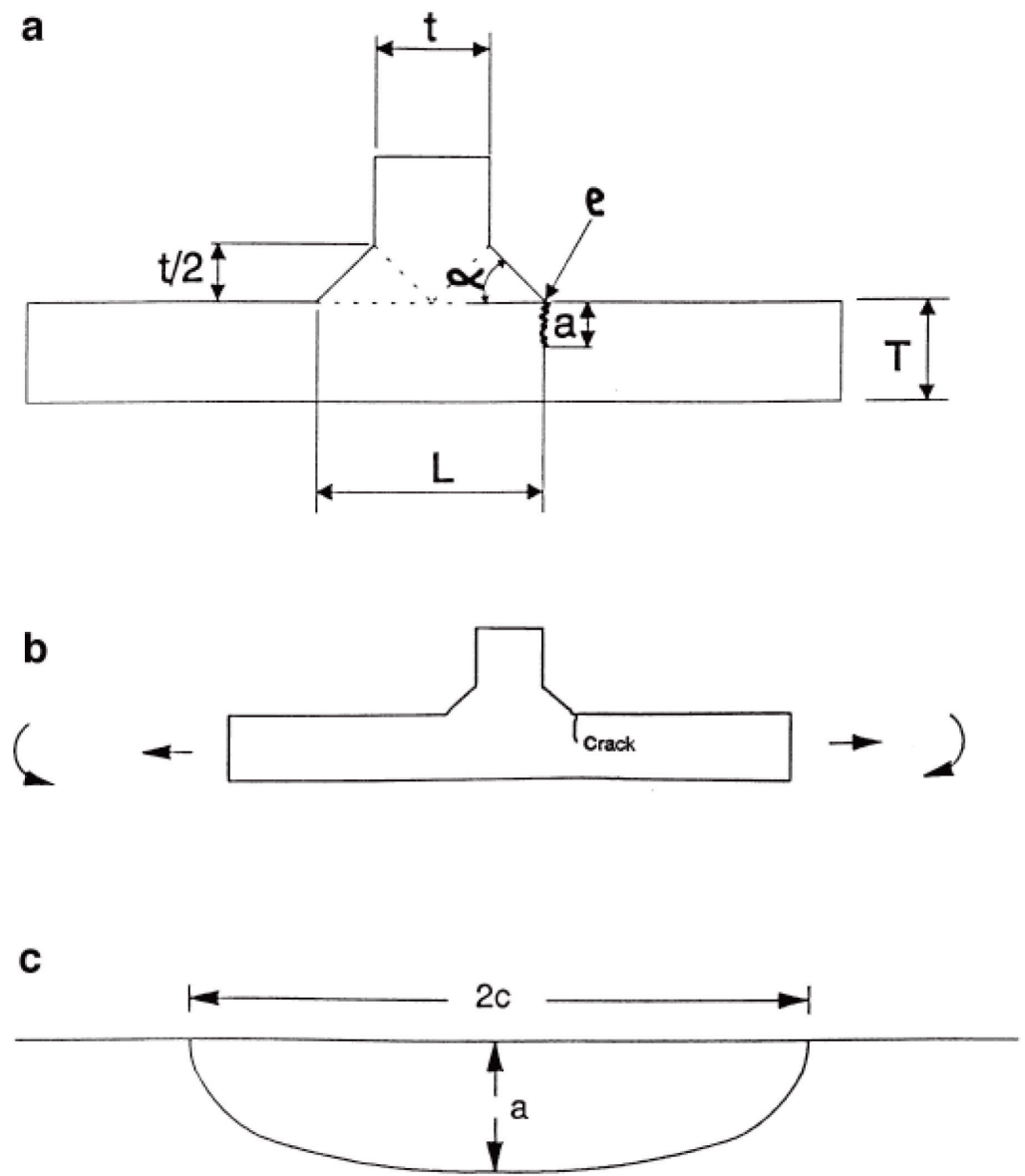

Fig. 2. (a) Local weld geometry studied (b) Geometry and loading used to derive stress intensity factors (c) Crack geometry (semi-elliptical crack).

Recently developed and unique Hellier-Brennan-Carr (HBC) T-butt weld toe surface stress concentration factor (SCF) [6] and stress distribution parametric equations [7] through the base plate thickness (i.e. the potential Mode I crack plane) are also available for similar ranges of geometric parameters and tensile (membrane) loading.

Crack Growth Equations. The Paris Law [8] is commonly used to predict the (Stage 2) fatigue propagation life for a component or structure containing a sharp initial crack. It does not take into 
account the influence of mean stress. Another equation which does incorporate the (second order) influence of mean stress on the propagation rate is the Forman Equation [9].

Computer Programs to Predict Fatigue Life. Two FORTRAN computer programs were written to predict the remaining fatigue life for a T-butt welded joint containing a semi-elliptical crack at the weld toe under tension (membrane) loading. The first of these programs uses the BDKH tension parametric equation in conjunction with the Paris Law, and is applicable to a stress-relieved joint. The second program uses the BDKH tension parametric equation together with the HBC tension parametric equation and the Forman Equation, and is applicable to both the as-welded and ultrasonically peened conditions where residual stresses are present.

\section{Experimental Results}

Residual Stresses. Although the nominal yield stress of the A350 grade plate is $350 \mathrm{MPa}$ the actual yield stress is generally higher, in this case averaging out to about $400 \mathrm{MPa}$. Ultrasonic peening was highly effective, leading to a residual stress redistribution with a maximum compressive stress of about $250 \mathrm{MPa}$ at the weld toe surface and a maximum tensile stress of $220 \mathrm{MPa}$, at a depth of almost $3 \mathrm{~mm}$ into the base plate (refer to Fig. 3 ).

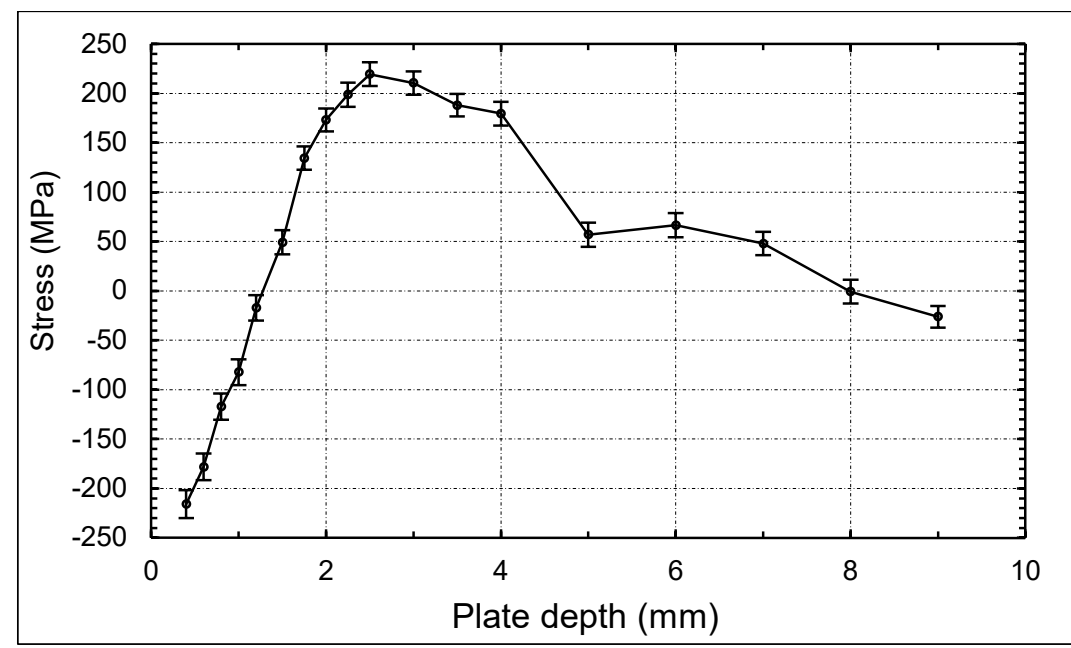

Fig. 3. T-butt weld toe residual stresses through the base plate after ultrasonic peening.

Since there are no measurements in the as-welded state, a typical as-welded residual stress distribution from the literature [10] was used instead, as shown in Fig. 4. The sample investigated using neutron diffraction with a $2 \times 2 \times 2 \mathrm{~mm}^{3}$ gauge volume was a T-plate fillet weld, joining two $25 \mathrm{~mm}$ thick plates. The plate material was BS 7191 grade $355 \mathrm{EMZ}$ structural steel, which is very similar to A350 grade steel, and represents a large group of steels commonly used in the nuclear and offshore industries. SMAW welding with standard filler metal was used. Both welds consisted of four weld passes in an alternating sequence between the two sides. For the purpose of this work, the residual stress distribution at the T-butt weld toe centre line was scaled horizontally to fit a $10 \mathrm{~mm}$ thick base plate.

Geometric, Material and Loading Parameters. Table 1 contains values of the geometric parameters selected for the present analyses.

The fatigue threshold, $\Delta K_{\text {Ith }}$, was taken as $3.2 \mathrm{MPa} \sqrt{\mathrm{m}}$. The Paris Law crack growth coefficient and exponent were $C=8.57 \times 10^{-12}$ (SI units) and $m=3$, respectively. Applied membrane stress varied from 0 to $100 \mathrm{MPa}$. The number of crack increments employed in the modelling was 10,000.

Preliminary Results. Fig. 5 shows the numerical crack growth results superimposed for: (a) aswelded; (b) stress-relieved; and (c) ultrasonically peened conditions. The analyses conducted assumed that a fatigue crack grows through a static residual stress field. As expected, it is apparent 
that the ultrasonically peened T-butt exhibited a longer fatigue life than the stress-relieved specimen, which in turn had a longer fatigue life than the as-welded specimen. It should be noted that the ultrasonically peened specimen had an initial crack depth of $1 \mathrm{~mm}$; when it had the same $0.1 \mathrm{~mm}$ initial crack depth as the other two specimens it exhibited no fatigue crack growth at all.

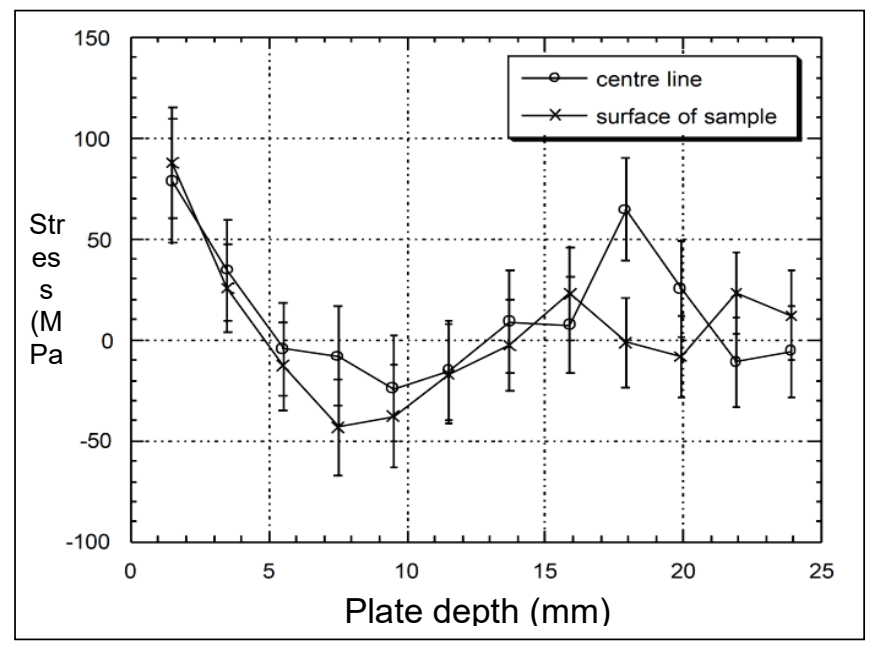

Fig. 4. Through-thickness residual stresses at T-butt weld toe centre line and surface of the sample as a function of base plate depth [10].

Table 1. Geometric parameters of T-butt joints.

\begin{tabular}{|c|c|}
\hline Geometric Parameter & Value \\
\hline Weld angle $[\alpha]$ & $45^{\circ}$ \\
\hline Weld toe radius $[\rho]$ & $0.1 \mathrm{~mm}$ \\
\hline Plate thickness $[T]$ & $10 \mathrm{~mm}$ \\
\hline Welded attachment width $[L]$ & $30 \mathrm{~mm}$ \\
\hline Initial semi-elliptical crack depth $\left[a_{\mathrm{i}}\right]$ & $0.1 \mathrm{~mm}$ or $1 \mathrm{~mm}$ \\
\hline Initial semi-elliptical crack width $\left[2 c_{\mathrm{i}}\right]$ & $2 \mathrm{~mm}$ or $20 \mathrm{~mm}$ \\
\hline
\end{tabular}

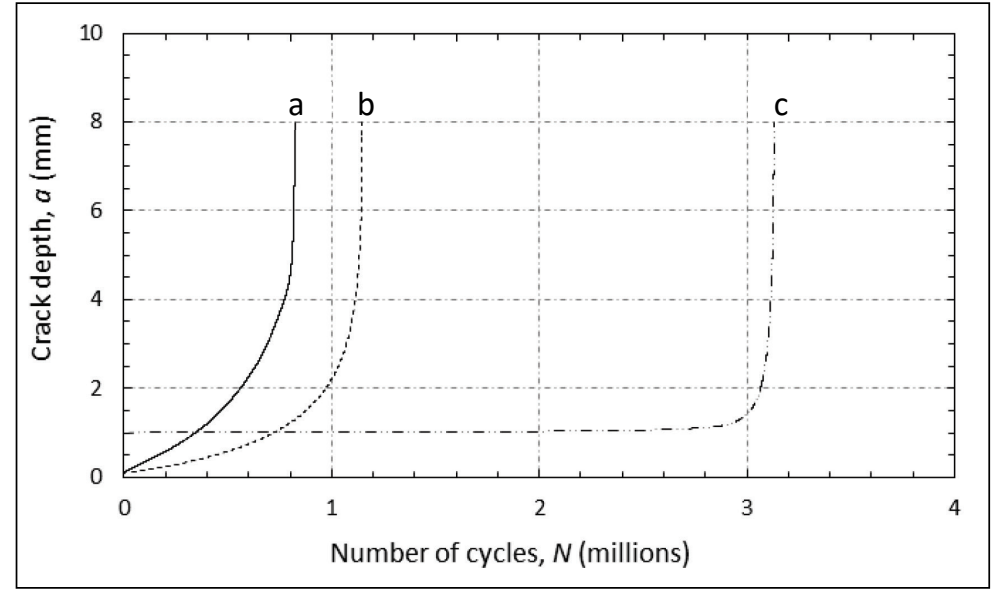

Fig. 5. Fatigue crack growth curves (a) As-welded (b) Stress-relieved (c) Ultrasonically peened specimens.

\section{Conclusions}


Ultrasonic peening was found to be very effective at modifying the residual stress distribution. As expected the as-welded residual stresses shortened the fatigue propagation life, whereas ultrasonic peening extended it or completely prevented fatigue crack growth.

\section{References}

[1] R.T. Yekta, S. Walbridge, Acceptance Criteria for Ultrasonic Impact Treatment (UIT), Ontario Ministry of Transportation, Provincial Highways Management Division, Highway Infrastructure Innovation Funding Program, Final Report No. HIIFP-110, Canada, February 2013.

[2] L. Lopez Martinez, Z. Barsoum, A. Paradowska, State-of-the-art: Fatigue life extension of offshore installations, in: Proc. 31st International Conference on Ocean, Offshore and Arctic Engineering (OMAE2012), Rio de Janeiro, Brazil, 1-6 July 2012, Paper 83044.

http://dx.doi.org/10.1115/omae2012-83044

[3] Esonix UIT, Application Guide, Post Weld Treatment for Fatigue Enhancement, Carbon Steel Welded Structures, Applied Ultrasonics, Revision 2.0, Revision Date: 28 June 2006.

[4] F.P. Brennan, W.D. Dover, R.F. Karé, A.K. Hellier, Parametric equations for T-butt weld toe stress intensity factors, Int. J. Fatigue 21 (1999) 1051-1062.

http://dx.doi.org/10.1016/S0142-1123(99)00090-0

[5] X. Niu, G. Glinka, Theoretical and experimental analyses of surface fatigue cracks in weldments, in: W.G. Reuter, J.H. Underwood, J.C. Newman (Eds.), Proc. Symposium on Surface-Crack Growth: Models, Experiments, and Structures, Sparks, NV, 25 April 1988, ASTM STP 1060, American Society for Testing and Materials, Philadelphia, PA, 1990, pp. 390-413.

http://dx.doi.org/10.1520/stp23445s

[6] F.P. Brennan, P. Peleties, A.K. Hellier, Predicting weld toe stress concentration factors for T and skewed T-joint plate connections, Int. J. Fatigue 22 (2000) 573-584.

http://dx.doi.org/10.1016/S0142-1123(00)00031-1

[7] A.K. Hellier, F.P. Brennan, D.G. Carr, Weld toe SCF and stress distribution parametric equations for tension (membrane) loading, in: Proc. Fatigue 2014, 11th International Fatigue Congress, MCG, Melbourne, 2-7 March 2014, Adv. Mater. Research 891-892 (2014) 1525-1530.

[8] P. Paris, F. Erdogan, A critical analysis of crack propagation laws, Trans. ASME, J. Basic Eng. 85 (1963) 528-534.

http://dx.doi.org/10.1115/1.3656900

[9] R.G. Forman, V.E. Kearney, R.M. Engle, Numerical analysis of crack propagation in cyclicloaded structures, Trans. ASME, J. Basic Eng. 89 (1967) 459-463.

http://dx.doi.org/10.1115/1.3609637

[10] P.S. May, R.C. Wimpory, G.A. Webster, N.P. O’Dowd, Determination of the Residual Stress Distribution in a Welded T-Plate Joint, Experimental Report, REST Instrument, Experiment Number 425, The Studsvik Neutron Research Laboratory (NFL), University of Uppsala, Studsvik, Sweden, 2000. 